\title{
Fracture Size Effect: Review of Evidence for Concrete Structures
}

\author{
By Zdeněk P. Bažant,, Fellow, ASCE, Joško Ožbolt, ${ }^{2}$ and Rolf Eligehausen ${ }^{3}$
}

\begin{abstract}
The paper reviews experimental evidence on the size effect caused by energy release due to fracture growth during brittle failures of concrete structures. The experimental evidence has by now become quite extensive. The size effect is verified for diagonal shear failure and torsional failure of longitudinally reinforced beams without stirrups, punching shear failure of slabs, pull-out failures of deformed bars and of headed anchors, failure of short and slender tied columns, double-punch compression failure and for part of the range also the splitting failure of concrete cylinders in the Brazilian test. Although much of this experimental evidence has been obtained with smaller laboratory specimens and concrete of reduced aggregate size, some significant evidence now also exists for normal-size structures made with normal-size aggregate. There is also extensive and multifaceted theoretical support. A nonlocal finite element code based on the microplane model is shown to be capable of correctly simulating the existing experimental data on the size effect. More experimental data for large structures with normal-size aggregate are needed to strengthen the existing verification and improve the calibration of the theory.
\end{abstract}

\section{NATURE OF PROBLEM}

As a result of many important studies, including Humphreys (1957), Rüsch et al. (1962), Leonhardt and Walter (1962), Kani (1967), Bhal (1968), Hsu (1968), McMullen and Daniel (1972), Taylor (1972), Hillerborg et al. (1976), Walsh (1976), Walraven (1978, 1990), Chana (1981), Petersson (1981), Reinhardt (1981a,b), Hawkins (1985), Iguro et al. (1985), Hillerborg (1985, 1989), Ingraffea (1985), Rots (1988, 1992) and others, it has been known that failure of concrete structures exhibits a size effect. For a long time the size effect has been explained statistically as a consequence of the randomness of material strength, particularly by the fact that in a larger structure it is more likely to encounter a material point of smaller strength. Various existing test data on the size effect were interpreted in terms of Weibull weakest-link theory [e.g. Mihashi and Zaitsev (1981) and Mihashi (1983)]. Later, however, it was proposed (Bažant 1984, 1986) that whenever the failure does not occur at the initiation of cracking, which represents most situations, the size effect should properly be explained by energy release caused by macrocrack growth, and that the randomness of strength plays only a negligible role [in detail see Bažant and Xi (1991)].

The size effect, however, does not follow the classical, linear form of fracture mechanics, in which all the fracture process is presumed to be happening at one point - the crack tip. Rather, the size effect in concrete structures must be explained by a nonlinear form of fracture mechanics that takes into account the localization of damage into a fracture process zone

\footnotetext{
'Walter P. Murphy Prof. of Civ. Engrg. and Mat. Sci., Northwestern Univ., Evanston, IL 60208.

${ }^{2}$ Res, Engr., Institut für Werkstoffe im Bauwesen, Stuttgart Univ., Germany.

${ }^{3}$ Prof., Institut für Werkstoffe im Bauwesen, Stuttgart Univ., Germany.

Note. Discussion open until January 1, 1995. To extend the closing date one month, a written request must be filed with the ASCE Manager of Journals. The manuscript for this paper was submitted for review and possible publication on January 27, 1992. This paper is part of the Journal of Structural Engineering, Vol. 120, No. 8, August, 1994. (C)ASCE, ISSN 0733-9445/94/0008-2377/\$2.00+\$.25 per page. Paper No. 3352.
} 
of a nonnegligible size. Such a size effect, which is characteristic of all quasibrittle materials (including rock, ice, various fiber and particle composites, modern tough ceramics, etc.), exhibits at increasing structure size a gradual transition from the case of plastic limit analysis, for which there is no size effect, to the case of linear elastic fracture mechanics, for which the size effect is the strongest possible.

The proper explanation of this size effect has been shown to lie in the release of strain energy due to fracture growth, producing damage localization instabilities [see, e.g., chapters 12 and 13 in the textbook by Bažant and Cedolin (1991)]. Prior to failure, distributed damage, consisting principally of microcracking, localizes into a narrow fracture process zone, which ultimately becomes the final, major crack. The localization is driven by the release of stored strain energy from the structure. In a larger structure, the strain energy is released from a larger zone, and so the total amount that would be released for a unit crack advance would be larger if the nominal stress were the same. However, because the energy required to produce a unit fracture extension is approximately independent of the structure size, the nominal stress at failure of a larger structure must be lower, so that the energy release would exactly match the energy required for the fracture formation.

The test data on the size effect in the structural engineering literature [analyzed systematically by Bažant and Kim (1984), Bažant and Sun (1987), and others] have turned out to be insufficient for understanding the phenomenon. Since the existence of the size effect was not suspected by most experimenters and was thought by others to be properly taken care of by statistical considerations and thus relegated to safety factors, the vast majority of experimental studies of brittle failures of concrete structures has not even examined the size effect. Those few studies that did explored only a rather limited size range and, unfortunately, did not adhere in most cases to the requirements of geometric similarity. In consequence, the size effect was mixed in most tests with many other effects, e.g., those of geometric shape, reinforcement ratio, bar sizes, concrete cover thickness, shear span, etc. Attempts to filter out these other effects and isolate the size effect were of little value, because of the scatter of the test results and limited knowledge of other factors that influence the failure load [see e.g. Bažant and Kim (1984) and Bažant and Sun (1987)].

Therefore, beginning in 1982, systematic experimental studies were initiated at Northwestern University. Because of cost limitations, all the tests were restricted to concrete with reduced maximum aggregate size (3/8, $1 / 4$, and $3 / 16$ in.). The test results, obtained under careful laboratory control, were quite systematic, with only a small scatter of the measured failure loads (which was not larger than in compression tests of concrete cylinders). Further extensive studies of the size effect for concretes with normal aggregate size have later also been performed (Iguro et al. 1985; Eligehausen et al. 1988; Eligehausen and Sawade 1989; Walraven 1990; Marti 1989; Wittman, et al. 1990; Bocca et al. 1990; Eligehausen et al. 1992). Among the first studies in which it was proposed that not only for specimens with notches but also for concrete structures the size effect ought to be explained by fracture mechanics were those of Hillerborg et al. (1976) and Reinhardt $(1981 \mathrm{a}, \mathrm{b})$. However, the use of linear elastic fracture mechanics in the study of Reinhardt $(1981 \mathrm{a}, \mathrm{b})$ gave a size effect that would be too strong for most practical situations.

The laboratory evidence for the fracture mechanics type of size effect in 
the basic kinds of brittle failures of concrete structures has by now become extensive, although the test data for large structures and normal-size aggregate are less extensive and for some failure types nonexistent. The main purpose of this paper is to review the present evidence, which now appears to be sufficient to conclude that the size effect ought to be taken into account in building codes as well as in the finite element programs for concrete structures. A secondary purpose is to demonstrate the capability of the recently formulated nonlocal finite element approach and microplane material model to describe the observed size effect.

\section{DESCRIPTION AND EXPLANATION OF SIZE EFFECT}

The size effect is defined by comparing the nominal strength (nominal stress at failure) $\sigma_{N}$ of geometrically similar structures of different sizes. For two-dimensional (2D) similarity, $\sigma_{N}=c_{n} F_{u} / b d$, and for three-dimensional similarity, $\sigma_{N}=c_{n} F_{u} / d^{2} ; F_{u}=$ maximum (ultimate) load of the structure; $b=$ structural thickness; $d=$ characteristic dimension (size), which may be introduced as any dimension of the structure, for example the beam depth; and $c_{n}=$ chosen coefficient introduced for convenience. One may set $c_{n}=1$, or one may use $c_{n}$ such that $\sigma_{N}$ would coincide with some convenient stress formula. For example, in the case of a simply supported beam of span $L$ and a rectangular cross section of depth $H$, loaded at midspan, one may set $d=H$ and $c_{n}=3 L / 2 H$, in which case $\sigma_{N}=3 F L / 2 b H^{2}=$ maximum elastic bending stress (note that $L / H$ and $b$ are constant for $2 \mathrm{D}$ similarity).

The size effect is understood as the dependence of $\sigma_{N}$ on the structure size $d$ (characteristic dimension). According to plastic limit analysis, as well as any theory in which the material failure is characterized in terms of stresses or strains, $\sigma_{N}$ is independent of the structure size, i.e., there is no size effect (this may be illustrated, e.g., by the elastic or plastic formulas for beams subjected to bending, shear or torsion). In linear elastic fracture mechanics, in which all the fracture process is assumed to occur at a point - the crack tip- $\sigma_{N}$ declines in proportion to $d^{-1 / 2}$. This means that the plot of $\log \sigma_{N}$ versus $\log d$ (Fig. 1) is an inclined straight line of slope $-1 / 2$, provided that the cracks at the moment of failure of structures of different sizes are geometrically similar. Note that the similarity of cracks at failure has been experimentally demonstrated for most, though not all, types of failures of concrete structures of different sizes, in the usual size range.

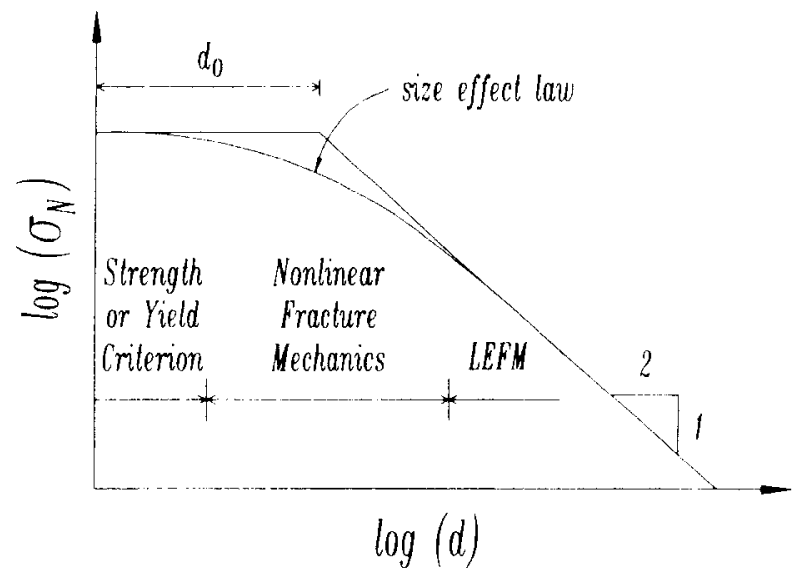

FIG. 1. Size Effect Law Proposed by Bažant (1984) 
In concrete structures the size effect is transitional between the strength (or yield) criterion (i.e., no size effect), represented by the horizontal line in Fig. 1, and the size effect of linear elastic fracture mechanics, represented by the curve in Fig. 1. For most practical purposes, this curve can be described by the size effect law (Bažant 1984):

$$
\sigma_{N}=B f_{i}^{\prime}(1+\beta)^{1 / 2} ; \quad \beta=d / d_{0}
$$

in which $f_{t}^{\prime}=$ tensile strength of concrete, introduced for convenience; and $B, d_{0}=$ two constants, to be determined either experimentally or by a more sophisticated analysis (c.g., using a finite element code that is able to realistically predict softening and failure process in a quasibrittle material such as concrete).

For $d \leq d_{0}$, (1) yields $\sigma_{N}=B f_{t}^{\prime}=$ constant, which means that the size effect disappears (see the horizontal asymptote in Fig. 1). For $d \gg d_{0}$. (1) reduces to $\sigma_{N}=B f_{i}^{\prime} \beta^{-1 / 2}$ or $\log \sigma_{N}=-(1 / 2) \log d+$ constant, which gives in Fig. 1 a straight-line asymptote of downward slope $-1 / 2$. Thus, the asymptotes of the size effect curve given by (1) are the plastic limit analysis and the linear elastic fracture mechanics. The intersection point of the horizontal and inclined asymptotes is obtained by setting $B f_{t}^{\prime}=B f_{t}^{\prime} \beta^{-1 / 2}$, which yields $\beta=1$ or $d=d_{0}$ (Fig. 1). Obviously, structures of sizes $d>$ $d_{0}$ are closer to linear elastic fracture mechanics than to plasticity, i.e., are predominantly brittle, and structures for which $d<d_{0}$ are closer to plasticity than to linear elastic fracture mechanics, i.e. are predominantly ductile. Therefore, the ratio $\beta=d / d_{0}$ has been called the brittleness number (in which $d_{0}$ introduces the effect of structure shape). Compared to the older definitions of brittleness number according to Gogotsi et al. (1978), Homeny et al. (1980), Hillerborg (1985), and Carpinteri $(1982,1986)$, this definition has the advantage of being independent of structure shape, which is achieved by means of dividing $d$ by $d_{0}$. For these previous definitions, the same value of the brittleness number, say 3 , can mean a very brittle behavior for one structure shape and a very ductile behavior for another structure shape. Thus, only the brittleness of structures of the same shape can be compared.

For some structures, for example the geometrically similar panels in Fig. 2 , which are initially under uniform stress, (1) can be derived by elementary analysis. The panels of different sizes are assumed to have in the middle of the left side a weak spot, from which fracture originates. The fracture front may be considered in the form of a crack band of a certain width $h$ that is approximately a material property, independent of the structure size. Furthermore, based on tests or more sophisticated analysis, it is assumed that, at maximum load, the length of fracture, $a$, is proportional to the panel

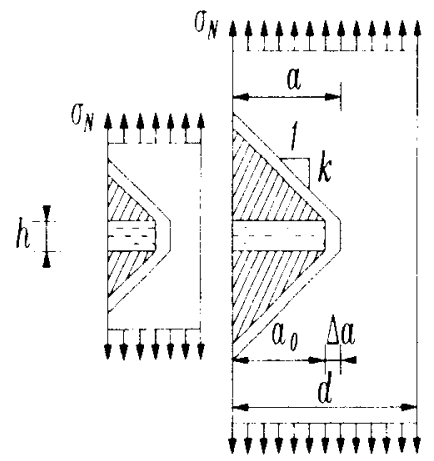

FIG. 2. Crack Band Propagation 
dimension $d$, i.e. ald $=$ constant. Formation of a crack band may be imagined to relieve stress and release the initial strain energy of density $\sigma^{2} / 2 E$ from the cross-hatched areas in Fig. 2 ( $E$ = elastic modulus of concrete). When the fracture extends by $\Delta a$, the initial strain energy that is released into the fracture front comes from the dotted strip of horizontal dimension $\Delta a$. (Although the idea of the stress relief zone is, of course, only a crude approximation, it so happens that this type of analysis yields the correct form of the formula; this can be easily checked for linear elastic fracture mechanics.)

It is instructive to note that in a larger structure the energy that is released into the fracture extension $\Delta a$ is larger if the value of $\sigma_{N}$ is kept the same, because (for $a / d=$ constant) the energy is released from a larger zone. Since the energy dissipated by fracture per unit area of the fracture surface is approximately constant, being equal to the fracture energy of the material, $G_{f}$, the crack length and therefore the value of $\sigma_{N}$ for a larger structure must be less so that the total energy release would remain the same. This explains the size effect. Now, quantitatively, the strain energy released from the dotted strip is $\Delta W=(h \Delta a+2 k a \Delta a) \sigma_{N}^{2} / 2 E$ if $\Delta \sigma_{N}=0$ (i.e. at maximum load). Setting $\Delta W=G_{f} \Delta a=$ dissipated energy, one gets $\sigma_{N}^{2}[h+2 k(a / d) d]=2 E G_{f}$. Solving for $\sigma_{N}$, one can then bring the resulting expression to the form of the size effect law in (1), with $B=$ $\left(2 E G_{f} / h f_{t}^{\prime 2}\right)^{-1 / 2}$ and $d_{0}=h d / 2 a k$, in which $d / a=$ constant in case of geometric similarity.

For more complicated structural geometries, the foregoing type of simple reasoning becomes impossible. However, (1) can be derived generally by dimensional analysis and similitude arguments (Bažant 1984, 1987). This general derivation rests on two basic hypotheses: (1) The propagation of a fracture or crack band requires an approximately constant energy supply per unit length and width of fracture; and (2) the potential energy released from the structure due to fracture growth is a function of both the fracture length and the area of the cracking zone (fracture process zone) at the fracture front. If the potential energy release is a function of only the fracture length, the size effect is that of linear elastic fracture mechanics, and if it is a function of only the cracking area, there is no size effect. In the case of fracture test specimens of different sizes, similarity of the fracture shape and length is enforced by providing geometrically similar notches.

In real concrete structures, from which notches are absent, the size effect law (1) is applicable only under the following two additional hypotheses: (3) At $P_{\max }$, the fracture shapes and lengths in geometrically similar structures of different sizes are also geometrically similar; and (4) the structure does not fail at crack initiation. There is now extensive evidence, both experimental and numerical, showing that hypothesis 3 is at least approximately satisfied according to the experience with structure tests in the laboratory. Hypothesis 4 is rather well satisfied in most situations, and in fact good design practice ensures that.

Although the size effect law (1) is only approximate, its accuracy appears to be sufficient for many cases, such as the diagonal shear or pull-out, and for a sufficiently broad size range - up to about 1:20 (specimens up to one meter). However, there are some cases in which the size effect law tends to underestimate the nominal structure strength for large structure sizes. While the size effect law predicts $\sigma_{N} \rightarrow 0$ for $d \rightarrow \infty$, a change in failure mechanism may cause that the nominal strength may tend to a non-zero limit, when the structure size is increased. 
It must be emphasized that the size effect is defined for structures made of the same material. This means that the mix proportions and the maximum aggregate size $d_{a}$ for structures of different sizes must be considered the same. If $d_{a}$ is changed, one has a different material (and, for instance, the specific cement content must then also be changed). When $d_{a}$ is changed simultaneously with $d$, one must in fact tackle two independent problems: first, the effect of a change in size $d$ at constant $d_{a}$, and second, the effect of a change in $d_{a}$ at constant size $d$. The second problem is beyond the scope of this paper, but it might be noted that an approximate formula for introducing the effect of $d_{a}$ into the size effect law was proposed in the closure of the discussion of Bažant and Kim (1984).

The arguments for applying the size effect law may be summarized as follows.

1. If the load-deflection diagram exhibits post-peak softening [Fig. 3(a)] it can be generally caused only by buckling or fracture (damage). But buckling does not occur in the failures studied here.

2. If there is fracture, there is necessarily a size effect. Now which law should describe it? It depends whether the maximum load $P_{\max }$ is nearly equal to the crack initiation load $P_{c r}$ or is much larger.

3. The case $P_{\max } \approx P_{c r}$ occurs typically for metallic structures. But, for concrete, this case occurs only in some unreinforced structures, e.g., in the bending failures of unreinforced beams or slabs, which is practically important for unreinforced footings. (But for some unreinforced structures, such as dams, one has $P_{\max } \gg P_{c r}$ ). When $P_{\max } \approx P_{c r}$, the size effect is strongly statistical, as described by Weibull theory, and has also a deterministic component due to the finite size of the process zone, as clarified by Hillerborg et al. (1976) in their study of the modulus of rupture. Information on the initial flaws is important only when $P_{\text {max }} \approx P_{c r}$, as known from the classical fracture mechanics of metallic structures [Fig. 3(b)].

4. But the initial flaws are almost irrelevant when $P_{\max } \gg P_{c r}$, which includes most reinforced concrete structures, and also some unreinforced structures such as dams. The classical Weibull models are inapplicable when $P_{\max } \gg P_{c r}$, and the statistical size effect disappears for $d \rightarrow \infty$ if $P_{\max } \gg$ $P_{c r}$, as proved in Bažant and $\mathrm{Xi}$ (1991) (for small $d$, there is some statistical size effect, but weak and negligible).

5 . It is now important to note that good practice requires designing concrete structures in such a manner that $P_{\max } \gg P_{c r}$. This is indirectly enforced by many code provisions on reinforcement and detailing, and in some cases this is required by the code explicitly. Therefore, long major cracks, intersecting a major part of the cross section, necessarily develop before reaching $P_{\max }$. Then, as long as these cracks are geometrically similar [Fig. 3(c)], the size effect law (1) applies. The fact that these cracks are approximately geometrically similar over a broad size range has transpired, for many structure types, from testing as well as finite element studies. However, for a sufficiently broad size range, one may expect that the similarity of major cracks ceases to hold.

As already mentioned, the existence of large cracks (guaranteed when $\left.P_{\max } \gg P_{c r}\right)$ and their geometric similarity are two basic hypotheses in extending the size effect law from fracture specimens to real (unnotched) concrete structures. This applies only when the structures made of different 
a)

b)
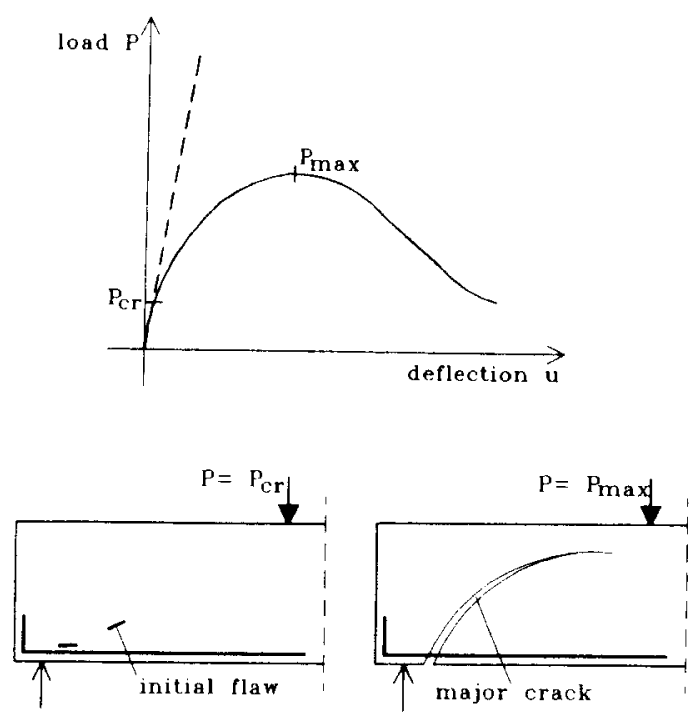

c)

similar

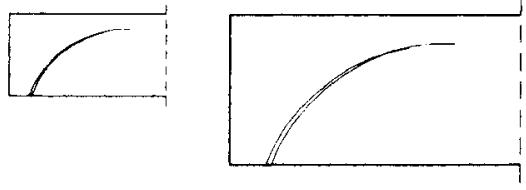

not similar
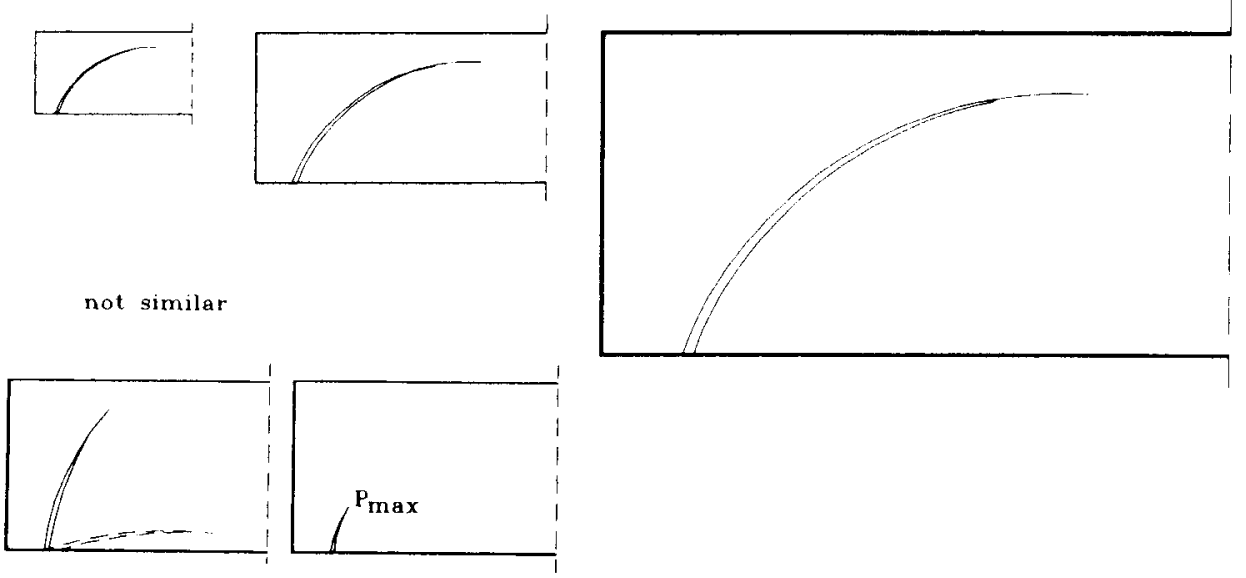

FIG. 3. (a) Structural Softening Behavior Caused by Fracture or Instability; (b) Failure at Crack Initiation $\left(P_{c r}<P_{\max }\right) ;(c)$ Similarity of Structure and Failure Mode at Peak Load $\left(P_{\max }\right)$

sizes are made of the same concrete. If the maximum aggregate size is changed, its effect must be assessed separately.

\section{REVIEW OF AVAILABLE EVIDENCE OF SIZE EFFECT}

The existence of a size effect approximately obeying (1) has by now been well established. The available evidence is extensive and multifaceted. It may be summarized as follows:

1. Theoretical arguments

a. Analytical solutions of energy release and localization instabilities for various simplified situations, of the type already described (Fig. 2).

$b$. Dimensional analysis and similitude arguments, already mentioned (Bažant 1984, 1987). 

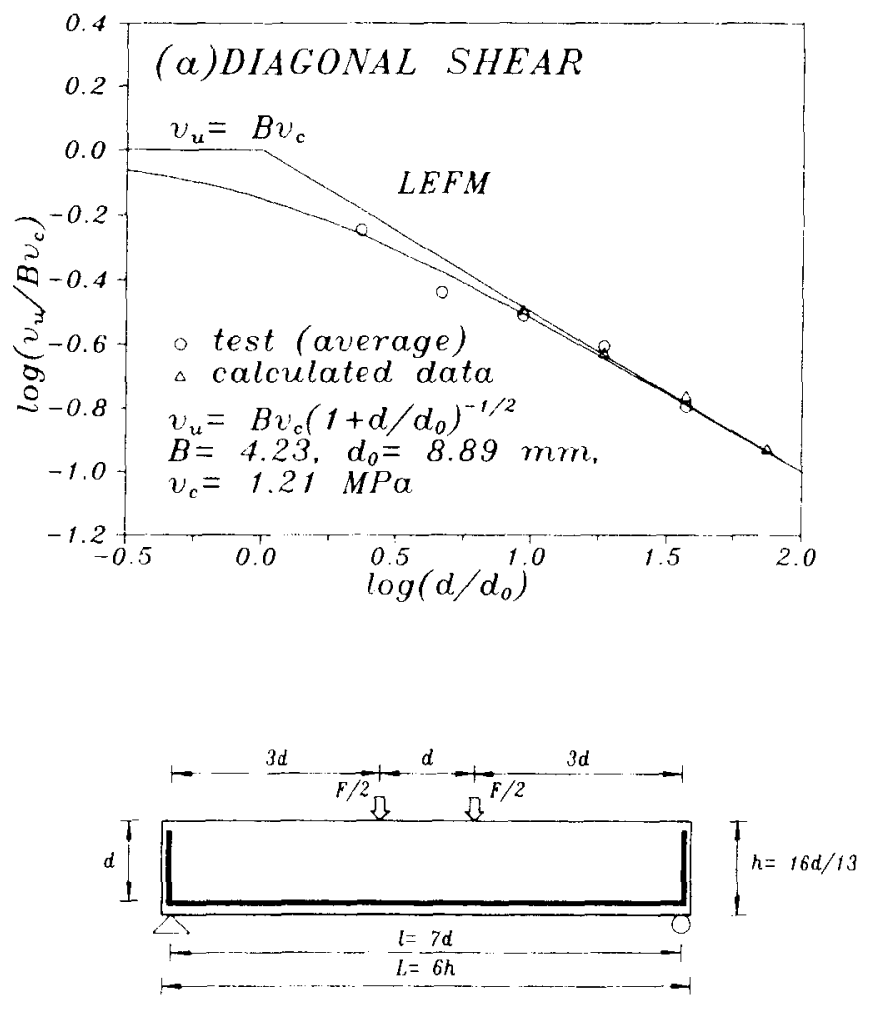

FIG. 4. Laboratory and Numerical Size Effect Tests of Geometrically Similar Reinforced Concrete Structures and Optimum Fits with Size Effect Law: (a) Diagonal Shear, $v_{t u}=\sigma_{N}=F_{u} / 2 b d$, Where $F_{u}=$ Peak Load; $d=$ Beam Depth; and $b=$ Beam Width

c. Numerical microstructural simulations on a supercomputer, in which the concrete is modeled as a random array of particles (hard aggregate pieces), with a softening interparticle force-displacement relation (Bažant et al. 1990; van Mier 1992).

d. Nonlinear fracture mechanics solutions based on the fictitious crack model with a gradually softening law for the crack bridging stresses (Hillerborg 1985).

$e$. Deterministic limit of a nonlocal generalization of Weibull-type statistical strength theory (Bažant and Xi 1991).

$f$. Finite element solutions based on the smeared crack approach (Bažant and Oh 1983; Bažant and Lin 1988; Rots 1988; Eligehausen and Ožbolt 1990; Cervenka et al. 1990) and discrete crack approach (Ingraffea 1985; Bocca et al. 1990).

2. Laboratory tests

a. Diagonal shear failure of longitudinally reinforced concrete beams without stirrups (Bažant and Kazemi 1991); see Fig. 4(a). (The size range was quite broad, 1:16. The longitudinal bars were provided with hooks at the ends, in order to prevent bar pull-out. In the absence of hooks, the diagonal shear failure was seen to be accompanied by pull-out, and the observed size effect was then weaker.)

$b$. Torsional failure of longitudinally reinforced beams without stirrups and unreinforced beams (Bažant et al. 1988); see Fig. 4(b). 

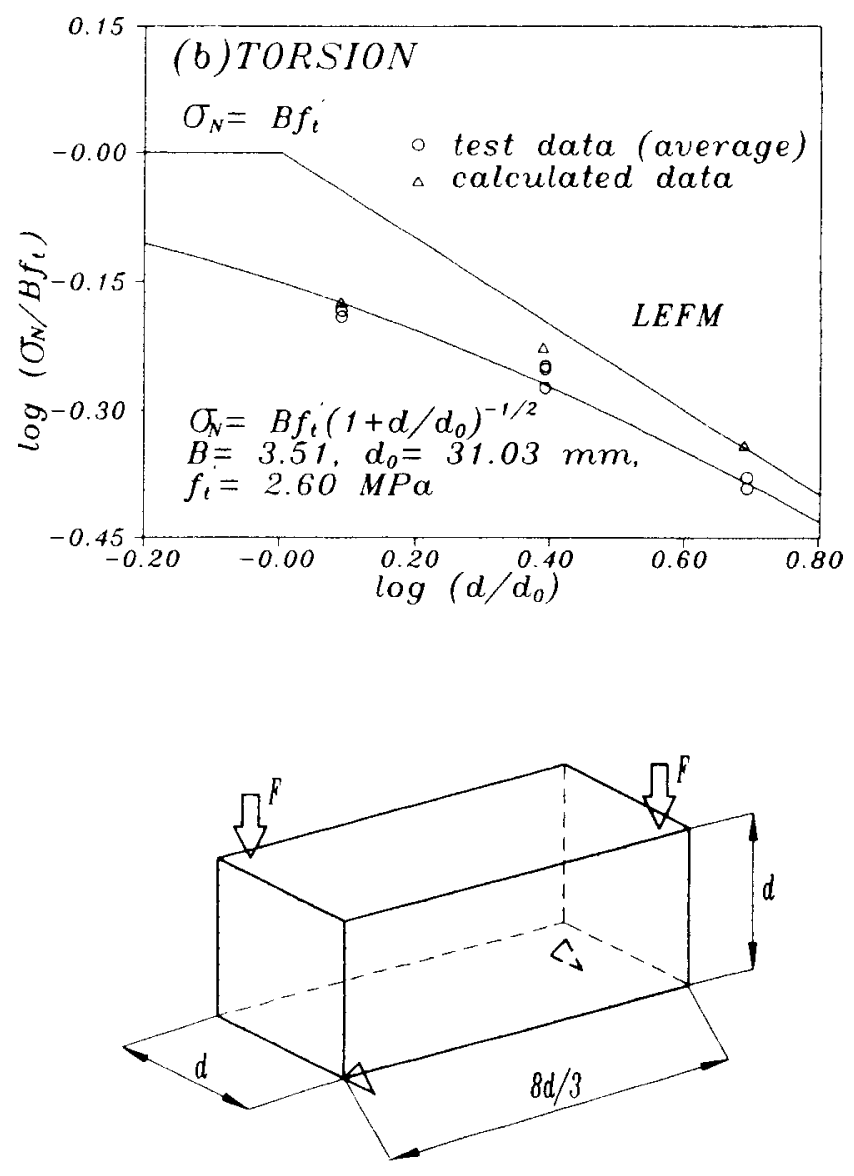

FIG. $4(b)$. Torsion of Unreinforced Concrete Beams, $\sigma_{N}=M_{t u} / 0.208 d^{3}$, Where $M_{u u}$ $=$ Torsion Moment at Peak Load; $d=$ Beam Depth and Width

c. Punching shear failure of slabs with a one-sided reinforcement mesh (Bažant and Cao 1987); Fig. 4(c).

$d$. Pull-out failure of deformed reinforcing bars (Bažant and Sener 1988); see Fig. 4(d).

$e$. Pull-out of headed anchors, with a conical failure surface (Eligehausen and Sawade 1989); see Fig. 4(e).

$f$. Double-punch compression failure of cylinders (Marti 1989); see Fig. $4(f)$.

g. Compression failure of tied columns, short as well as slender (Bažant and Kwon 1991); see Fig. 4(g).

h. Brazilian split-cylinder tests (Bažant et al. 1991); see Fig. 4(h).

In laboratory tests a. $-\mathrm{d}$. and g. $-\mathrm{h}$., the test specimens were of reduced size and made of microconcrete (maximum aggregate size $3 / 16$ to $3 / 8$ in.) with reduced-size reinforcing bars. Unless stated in the original report, the concrete tensile strengths shown in Fig. 4 were calculated as $f_{t}^{\prime}=6 \sqrt{f_{c}^{\prime}}$, where $f_{c}^{\prime}=$ standard cylindrical concrete compression strength (in psi).

The Brazilian test is the only one in which a systematic deviation from the size effect law according to (1) has been discovered. The size effect law is found to be followed for the size range of approximately $1: 10$. For larger sizes, the nominal stress at failure stops to decrease with the diameter of the concrete cylinder. As one reason, Bažant et al. (1991) suggested a 

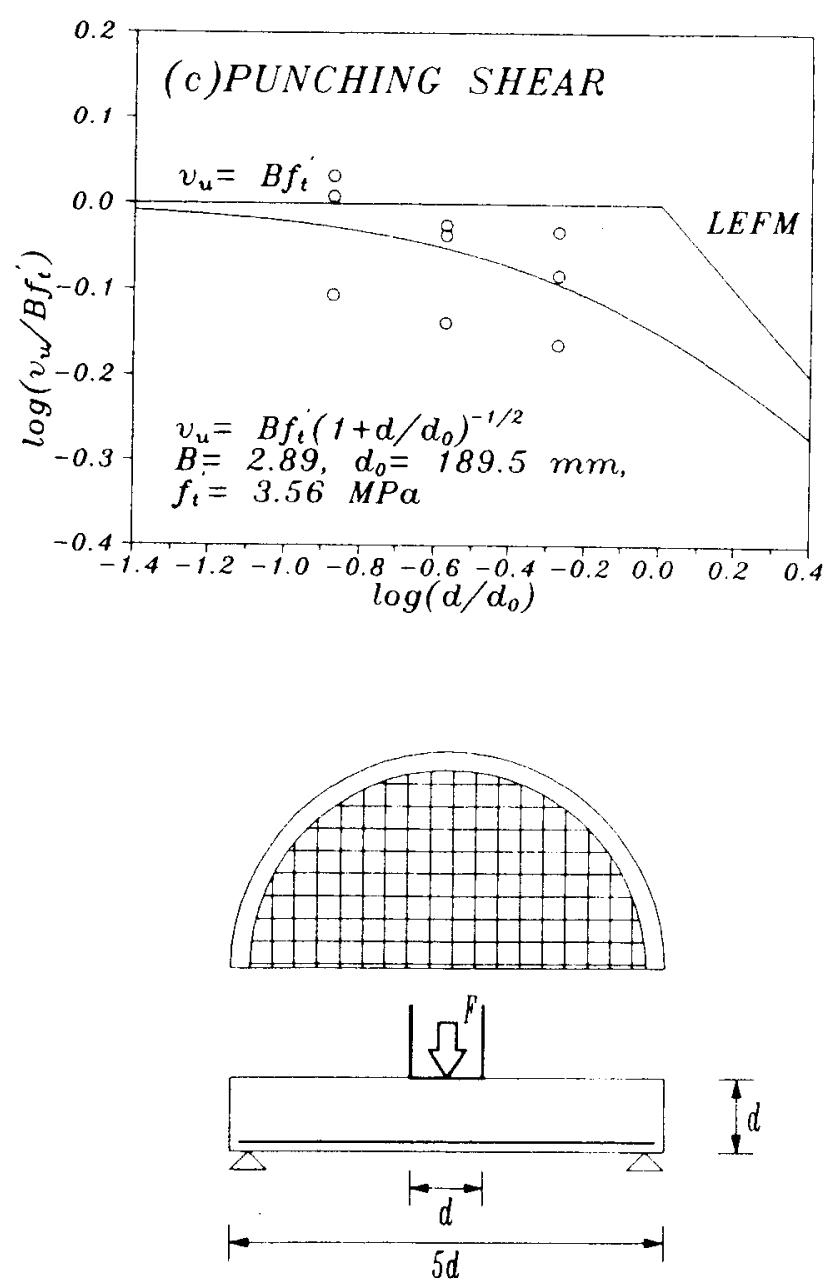

FIG. 4(c). Punching Shear of Slabs, $v_{u}=\sigma_{N}=F_{u} / \pi b d$, Where $d=$ Slab Thickness; and $b=$ Punch Diameter

transition to a different failure mechanism. At normal sizes, the maximum load achieved in the Brazilian test is governed by propagation of a fracture along the vertical symmetry line. However, the maximum load is not zero even for the case that the cylinder is cut in two halves before the test and the separate halves are then placed in the testing machine next to each other. In that case, failure is caused by frictional slip on a triangular wedge region under the loading platens. This slip is probably ductile, due to lateral confinement, and exhibits no size effect, which might explain that the size effect terminates with a horizontal plateau, as seen in Fig. $4(h)$. Another reason may be that the crack length at maximum load ceases to be proportional to $d$. Still another reason may be that the loads have been applied through metallic strips whose width has not been increased in proportion to $d$.

Eligehausen and Sawade (1989) performed pull-out tests on headed studs with different embedment depths $(d=130,260$, and $520 \mathrm{~mm})$. The concrete mix was constant (maximum aggregate size $16 \mathrm{~mm}$ ). Failure was caused by pulling out a concrete cone. The test results are plotted in Fig. 4(e). They follow quite closely the size effect law proposed by Bažant (1984).

In another study of concrete cone failure of headed studs with embedment depths $d=50$ to $450 \mathrm{~mm}$, all the structural dimensions where related 

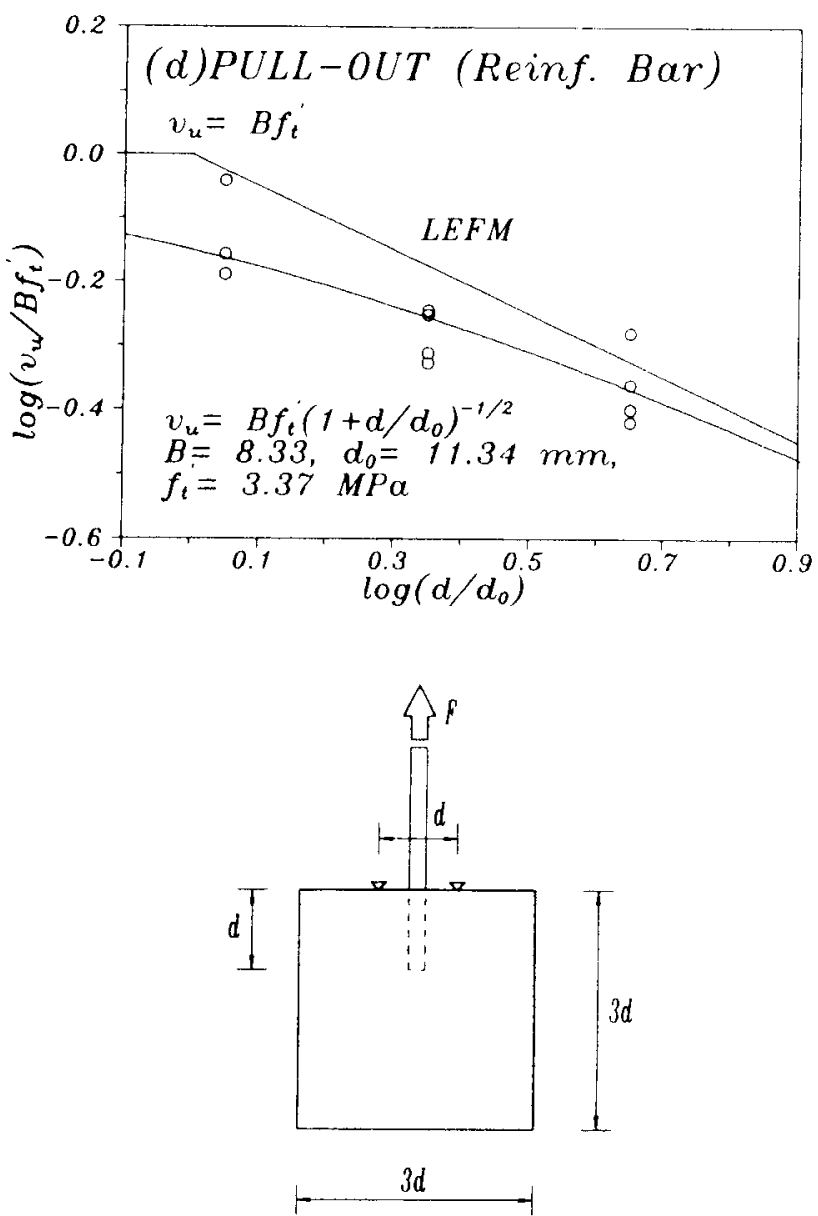

FIG. 4(d). Pull-Out of Reinforcing Bar, $v_{u}=\sigma_{N}=F_{u} / d_{b} \pi d$, Where $d=$ Embedment Depth and $d_{b}=$ Bar Diameter

proportionally to the embedment depth (Eligehausen et al. 1992). The concrete mix was kept constant. The test results can be approximated by the size effect law quite well.

Eligehausen et al. (1991) evaluated the results of 209 tests with headed anchors carried out at different laboratories. The failure was caused by pulling out a concrete cone. The tests were done on concretes of different mixes and different strengths. Therefore the measured failure loads were normalized to a cube compression strength $f_{c c}=25 \mathrm{MPa}$ by multiplying them with the factor $\sqrt{25 / f_{c c}}$. The normalized failure loads are plotted in Fig. 5 as a function of the effective embedment depth $d$. The failure load increases nearly in proportion to $d^{1.5}$, which means it follows the linear elastic fracture mechanics (LEFM) solutions. A strong size effect close to LEFM could of course be expected, since the observed fracture process zone is relatively small (Eligehausen and Sawade 1989; Eligehausen and Ožbolt 1990). Similar results were found for expansion anchors (Eligehausen et al. 1988).

The size effect law according to (1) has also been confirmed by Walraven and Lehwalter (1990) for the shear strength of normal beams and deep beams without shear reinforcement. They analyzed the results of a number of test series of different authors. The test specimens were designed to check the size effect. The results, which are plotted in Figs. 6 and 7 , are seen to 

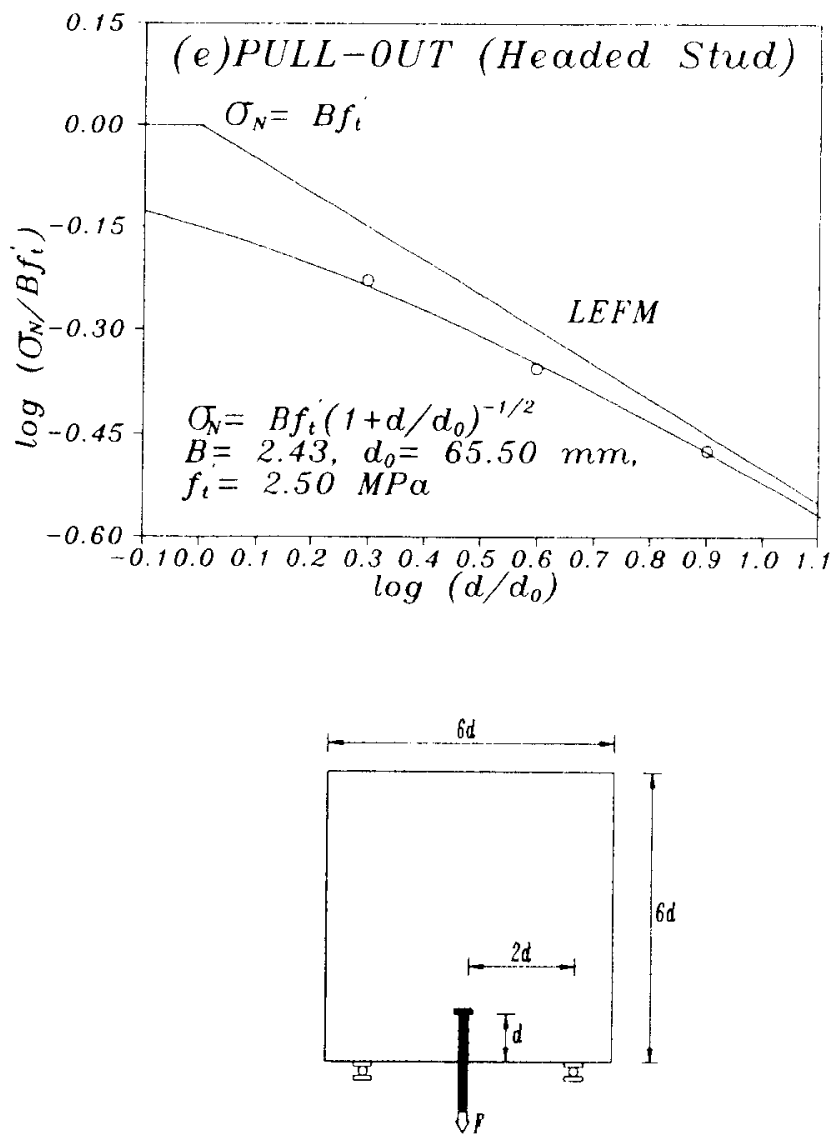

FIG. 4(e). Pull-Out of Headed Stud Embedded in Concrete Block, $\sigma_{N}=F_{u} / A$, Where $A=$ Surface Area of Pull-Out Cone Base Defined by Average Angle between Concrete Cone Surface and Concrete Surface $\alpha=35^{\circ}$

be described quite well by the size effect law, for both slender beams (Fig. 6) and deep beams (Fig. 7) up to sizes of about $1 \mathrm{~m}$.

Marti (1989) performed tests on concrete cylinders of different sizes loaded up to failure in double-punch compression. Normal concrete has been used, with a constant maximum aggregate size of $10 \mathrm{~mm}$. The diameters of the cylinders have been proportionally scaled in the range $d=76$ to $1,220 \mathrm{~mm}$ (1:16). As shown in Fig. $4(f)$, the results of the study show a good agreement with the size effect law.

The foregoing experimental evidence is rather broad, robust and clear. It was not clear in the numerous test data obtained previously. The reason is that the previous tests were not designed to reveal the size effect or to check any particular theory. As generally agreed in physical sciences, in order to prove or disprove a theory it is necessary to formulate it first as a hypothesis and then design the experiment according to this hypothesis. One reason why the aforementioned tests provided a conclusive picture is that they were designed to prove or disprove (1).

\section{COMPARISONS WITH NONLOCAL MICROPLANE MODEL}

\section{Finite Element Code}

To model concrete fracture and size effect, the most important requirement for a finite element code is that it must be insensitive to the mesh 


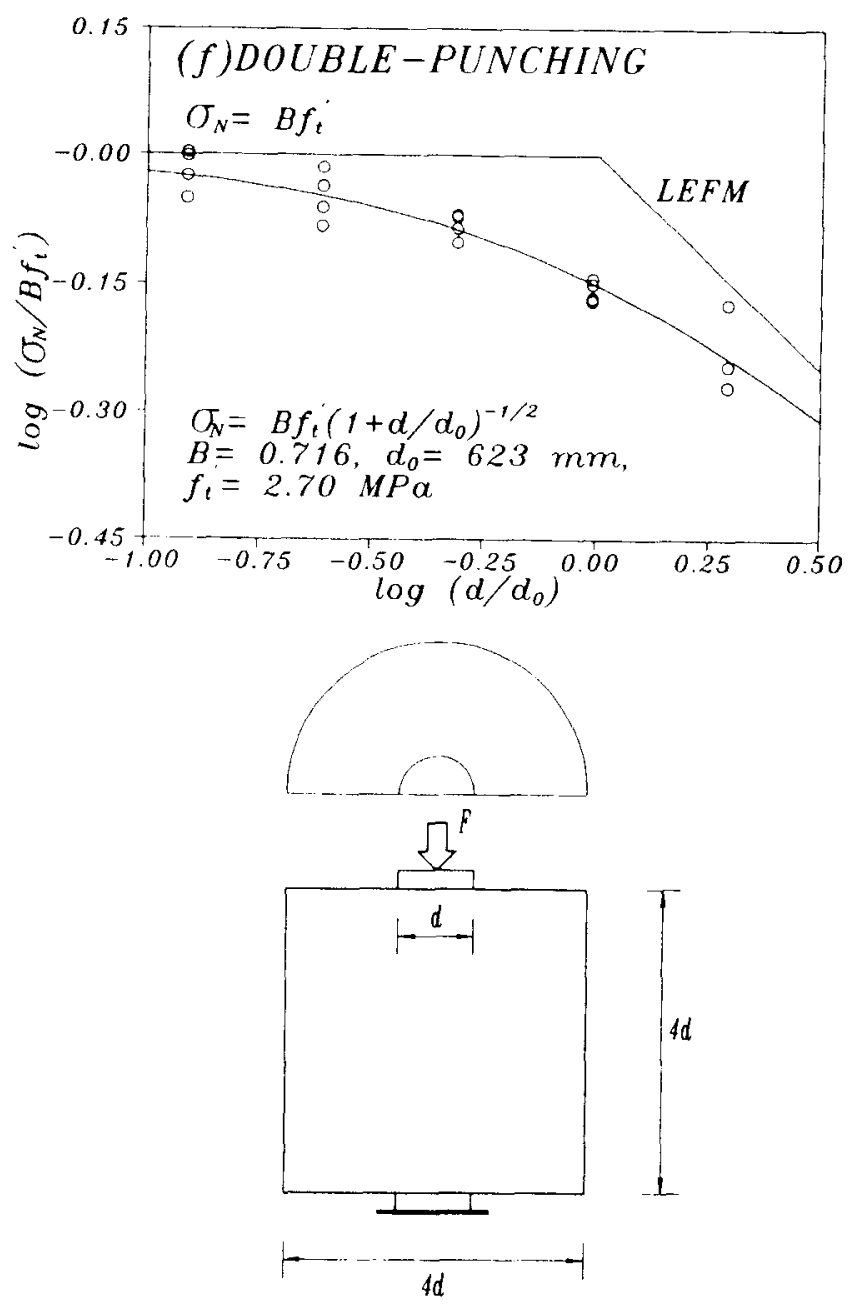

FIG. 4(f). Double-Punching Tests on Concrete Cylinders, $\imath^{\prime \prime}=\sigma_{N}=0.4 F_{u} / d^{2}$, Where $d=$ Cylinder Diameter

shape (orientation) and mesh size. Mesh shape sensitivity in finite element analysis is caused by the fact that the material softening (microcracking) is not modeled correctly (shear locking), while mesh-size sensitivity is a consequence of strain softening and is manifested as localization of energy dissipation into a zero volume. To avoid mesh-size sensitivity and simulate brittle failures including the size effect, the finite element code must be endowed with what has been called a localization limiter - a mathematical device that prevents localization of damage into a zone of zero volume. Alternatively, correct prediction can be obtained by a finite element code with discrete cracks characterized by a softening crack-bridging law. Such a code, however, appears to be less versatile in general situations.

The simplest localization limiter-a mere restriction on the minimum element size coupled with adjustment of the postpeak slope of the stressstrain diagram for larger than minimum sizes-is used in the crack band model. However, there is now much evidence that, because of mesh-shape sensitivity, finite element codes based on the crack band model cannot always correctly simulate brittle failures of concrete structures (de Borst 1991; de Borst and Rots 1989; Ožbolt and Eligehausen 1991; Rots 1992; Petrangeli and Ožbolt 1992). In fact, mesh-shape sensitivity of the crack band model seems to be too large, and generally this model is applicable only if the 

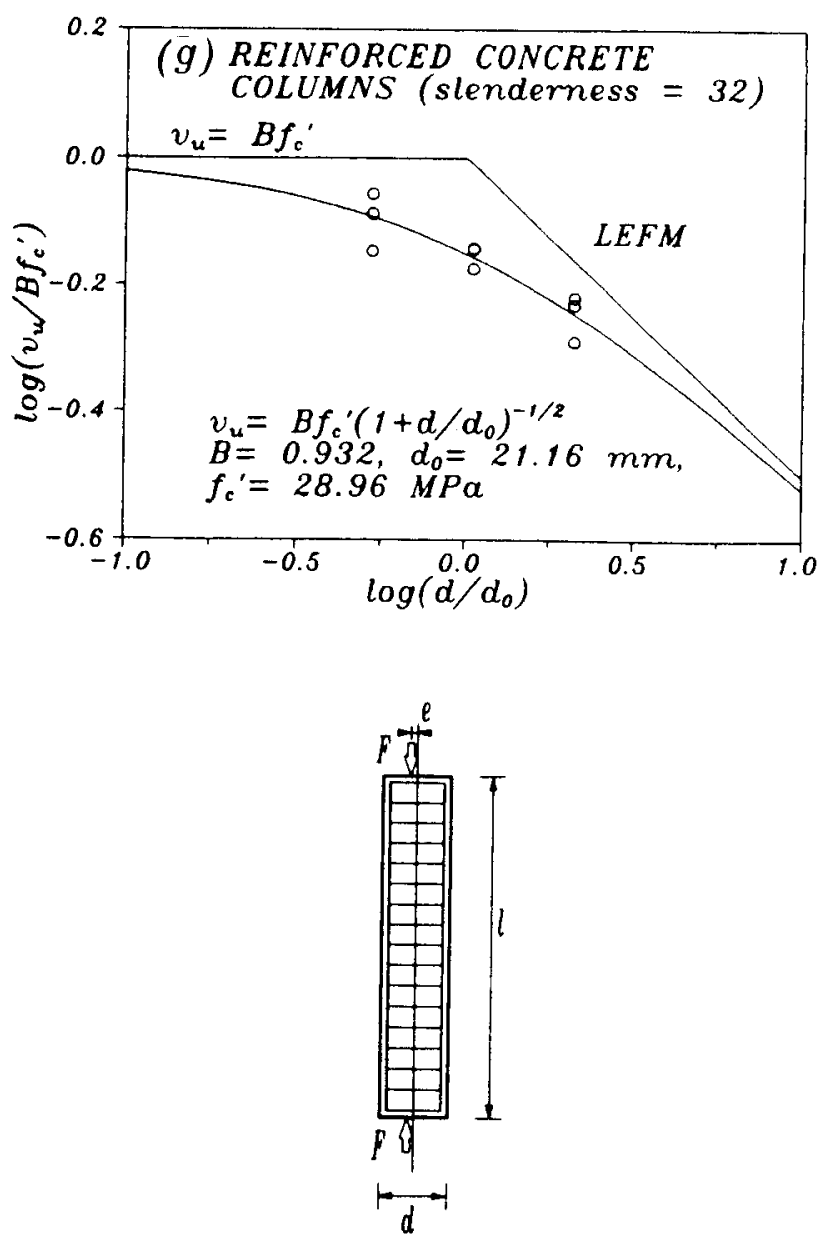

FIG. 4(g). Reinforced Concrete Columns (Slenderness $=32$ ), $\sigma_{N}=F_{u} / d^{2}$, with $d$ $=$ Cross-Section Size

cracking is parallel to the mesh lines. This means that the crack pattern should be known in advance when generating the finite element mesh.

Therefore, more general nonlocal codes with material models that are able to model the material softening process more realistically are required. It has been demonstrated that the nonlocal microplane model does not exhibit spurious mesh sensitivity (Ožbolt 1992). It provides a powerful tool in general three-dimensional smeared-cracking finite element analysis of concrete and reinforced structures.

A key parameter in the nonlocal approach is the value of the characteristic length $l$, which defines the size of the representative volume. In the numerical calculations, the characteristic length was chosen such that, in a certain test, the failure load of the medium size specimens would be matched correctly and then this value was kept constant when analyzing the specimens of different sizes. The optimum values of the ratio $l / d_{a}$ of the characteristic length $l$ to the maximum aggregate size $d_{a}$, indicated in Fig. 8, show substantial variation from one type of specimen to another. This variation seems broader than one could explain by differences in the composition of concrete. Apparently $l$ is not a material constant but a material function depending on the strain and stress fields in the neighborhood of a point, especially for points in the fracture process zone. The law governing the value of $l / d_{a}$ needs to be researched. 

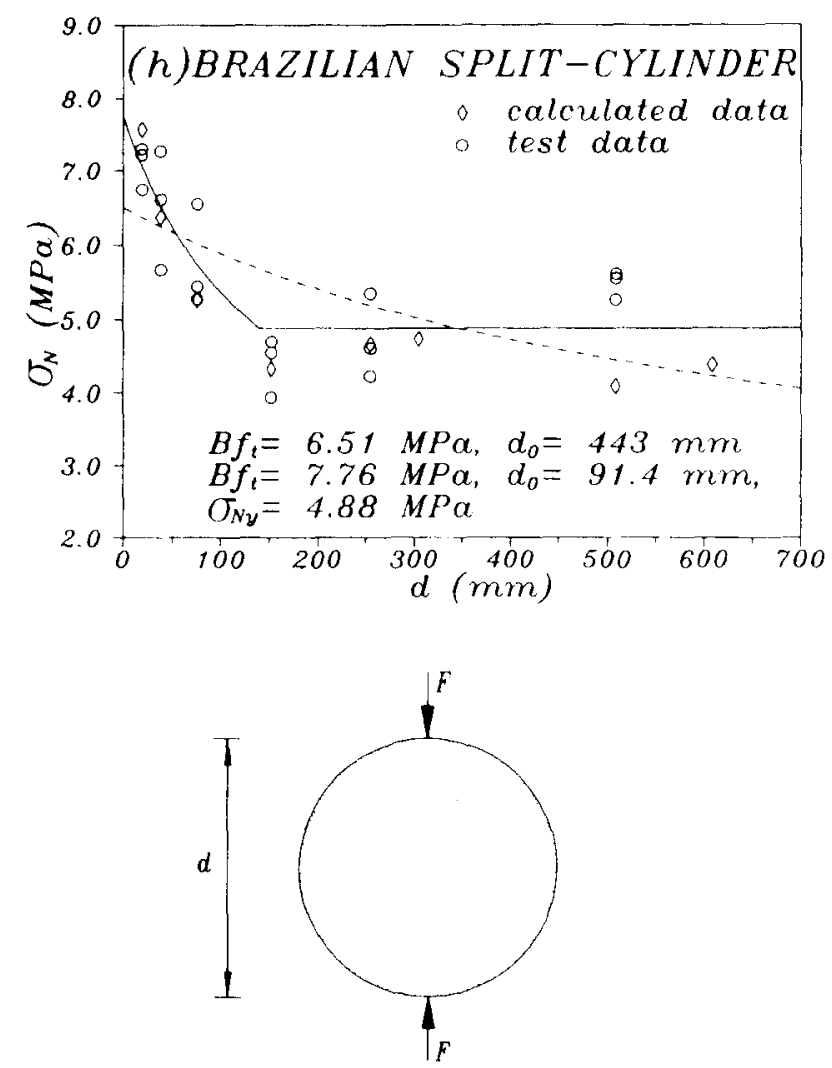

FIG. 4(h). Brazilian Split-Cylinder Tests, $\sigma_{N}=2 F_{u} / \pi b d$, Where $b=$ Cylinder Thickness; and $d=$ Cylinder Diameter

In nonlocal codes, it is important that the stress-strain relation describe quite realistically not only tensile cracking and fracture, but also the nonlinear triaxial behavior under various stress or strain histories, for both tensile and compressive stress states. A very powerful and general description of such behavior is provided by the microplane model. Its advanced form, agreeing with all the basic multiaxial test data for concrete, was presented in Bažant and Prat (1988).

In the microplane constitutive model, there is no need to use the stress and strain invariants. The tensorial invariance restrictions are satisfied automatically by combining the stresses acting on planes of all orientations within the material, called the microplanes (the reason for this term is that the constitutive properties specified on these planes approximately simulate the microstructural behavior, e.g., behavior on the interparticle contact planes, interfaces, microcracks, etc.). The constitutive properties are entirely characterized by a relation between the normal and shear components of stress and strain on the microplanes. The microplane strain components are assumed to be the projections of the macroscopic continuum strain tensor. The macroscopic stress tensor is obtained by integrating the stresses from all the microplanes according to the virtual work principle.

In the microplane model, the strain calculated for each integration point of each finite element, and each loading stage of each iteration, is first decomposed into components on a discrete set of microplanes [typically 21 of them, see Bažant and Ožbolt (1990)]. After calculating the stresses from the strains on all the microplanes, the macroscopic stress tensor is obtained by summation over these microplanes, which approximates an integral over 


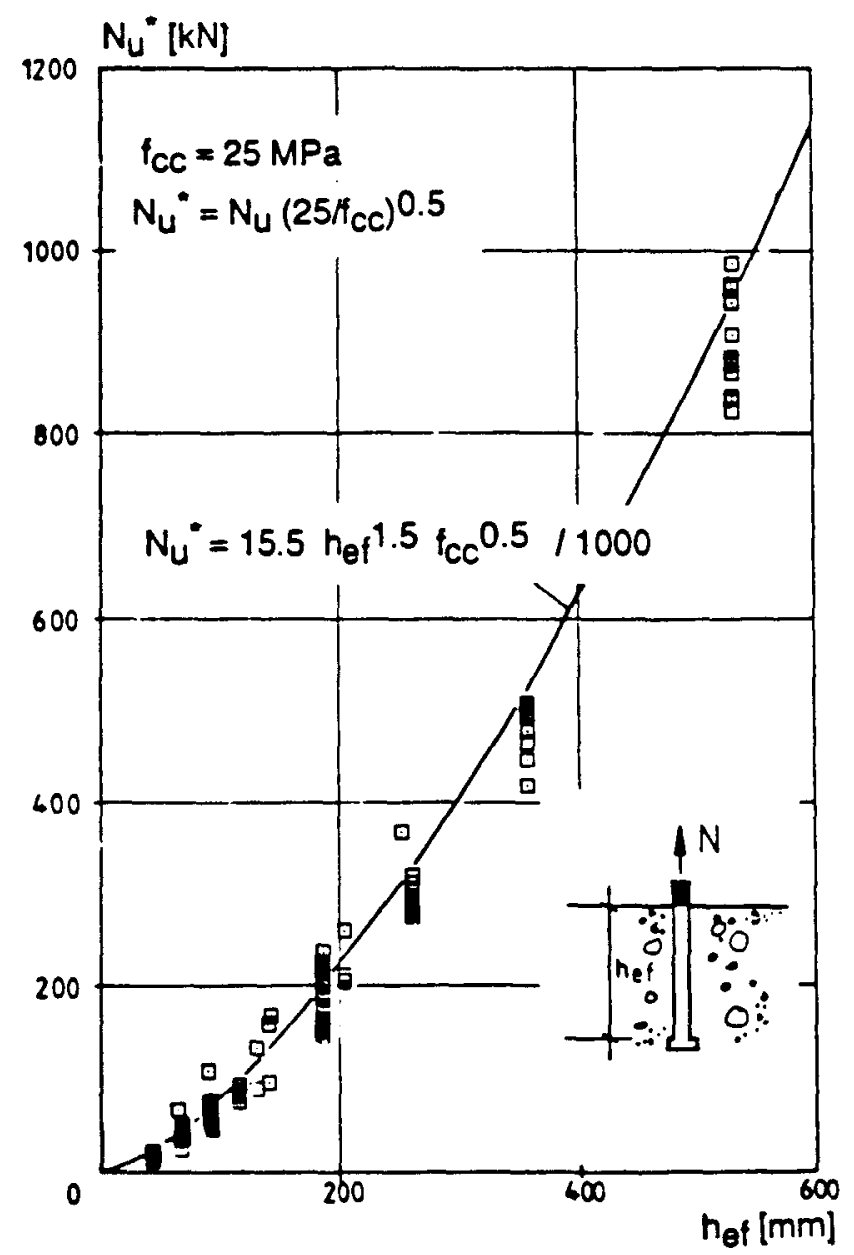

FIG. 5. Size Effect in Pull-Out of Headed Stud; Comparison Between Test Data and Proposed Formula Based on LEFM (Eligehausen et al. 1991)

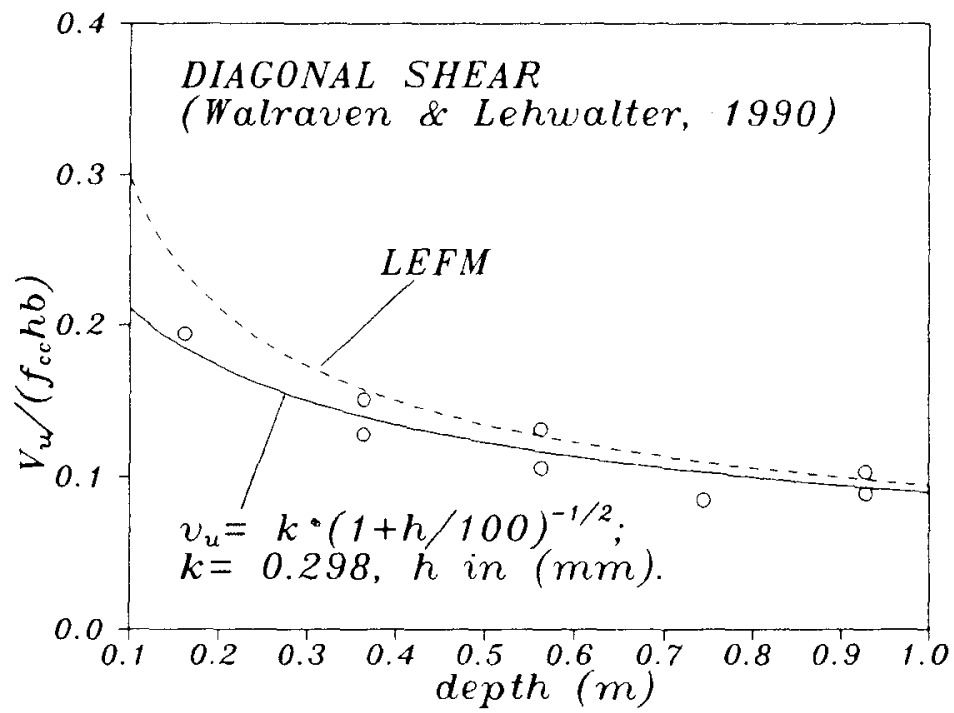

FIG. 6. Size Effect in Diagonal Shear Failure of Slender Beams without Shear Reinforcement; Comparison between Test Results, Formula Proposed by Walraven and Lehwalter (1990) and LEFM 


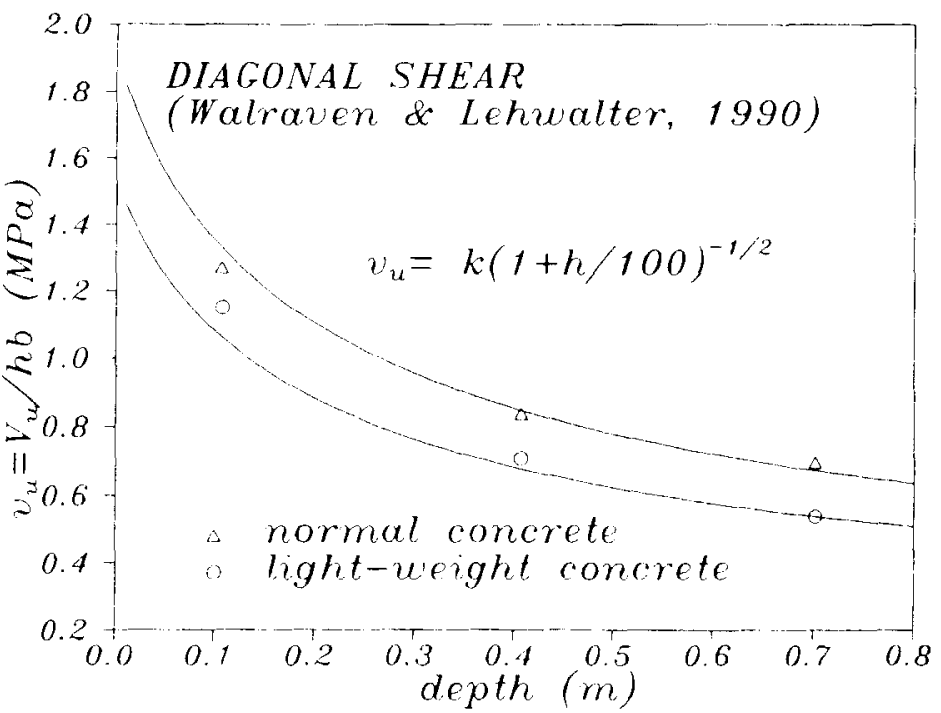

FIG. 7. Same as Fig. 6 but Using Deep Beams for Two Different Concrete Types (Normal and Lightweight Concretes)

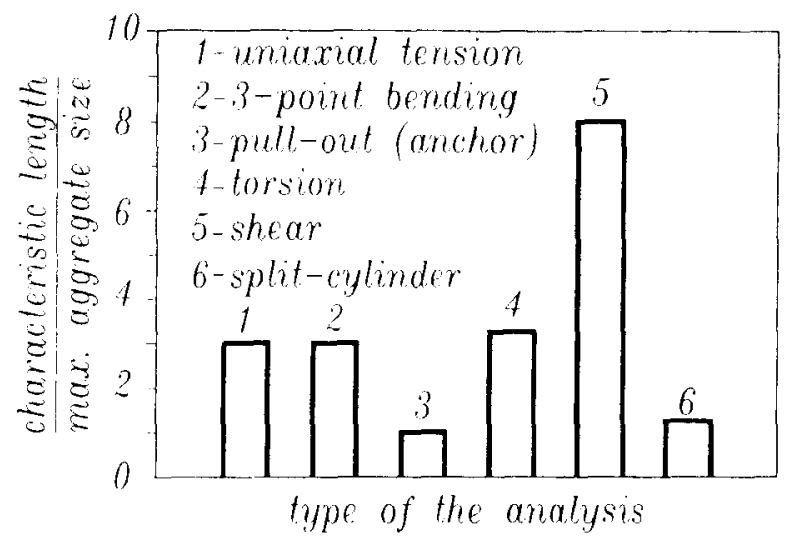

FIG. 8. Relation between Different Types of Analysis and Characteristic Length /

all spatial orientations of the microplanes. Obviously, this process adds considerable further computational work. Initially it was thought that this would preclude applications in large finite element codes, and the same was thought of the nonlocal averaging over all the adjacent finite elements. However, by virtue of the great recent advances in computer power, these two problems are no longer unsurmountable. It is now possible to run a large nonlocal finite element program with thousands of degrees of freedom on a desk microcomputer (with the Intel 486 chip).

To demonstrate the power of the nonlocal microplane code, the failure loads for some of the test specimens shown in Fig. 4 have been calculated. The results are plotted in Figs. $4(a, b, h)$ and Fig. 9. Except for the pullout of headed anchors, the experimental results are also plotted for comparison. The size effect law giving the best fit of the experimental data is plotted as a solid curve. The agreement between experimental and numerical results is seen to be generally quite acceptable. For the pull-out of headed anchors (Fig. 9), only the calculated data are given because the assumed geometry of the specimens analyzed differs from the geometry of the specimens tested.

As mentioned earlier, the nonlocal microplane model leads to close agree- 


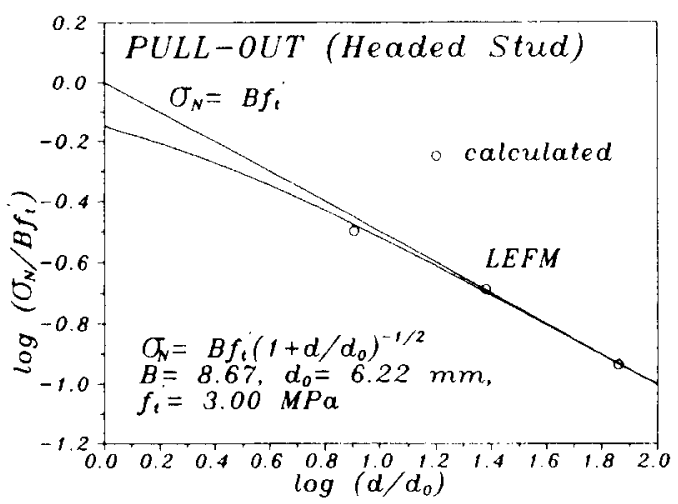

FIG. 9. Size Effect in Pull-Out Failure of Headed Stud Embedded into Concrete Block, Numerical Results

ment with the existing basic triaxial test data under various multiaxial stress histories, including compressive stress states. These capabilities appear to be quite important for some applications, such as the modeling of the termination of the size effect observed in the Brazilian split cylinder test [Fig. $4(h)]$.

The success of the present fitting of the size effect test data at the same time provides a further justification for explaining the size effect by means of fracture-mechanics-type energy release. The finite element code used was deterministic, and thus no statistical size effect due to random strength can be present in the finite element results.

Recently, the microplane model has been improved (Ožbolt and Petrangeli 1993) such that it is now able to model more realistically the evolution of cracking in arbitrary direction in general three-dimensional codes, with material discontinuity incorporated in the material model. The model has been also coupled with the new nonlocal approach that is based on the microcrack interactions (Bažant 1992: Ožbolt 1992).

\section{CONCLUSIONS}

1. There is now extensive laboratory experimental evidence proving that essentially all the types of brittle failures of concrete structures exhibit a strong size effect due to energy release.

2. The theoretical support for the size effect due to energy release is now strong and multifaceted, coming from various directions and offering a coherent picture. Under the conditions that: (1) The maximum load is much larger than the crack initiation load; (2) the major cracks at maximum load occupy a substantial portion of the cross section, and (3) are geometrically similar for specimens of different sizes, the size of the crack at maximum load is assumed to be approximately proportional to the structure size. Then the size effect law (1) is valid. The aforementioned conditions appear to be satisfied in most applications, but an exception exists-Brazilian splitting tests of a very broad size range.

3. The nonlocal microplane finite element code provides a realistic material model for smeared cracking analysis. This model prevents the localization of damage into a zero volume and can correctly predict the size effect in brittle failures of concrete structures.

4. Further experimental data for large structures with normal-size ag- 
gregate are needed to strengthen the verification and improve the calibration of the theory.

\section{ACKNOWLEDGMENT}

Partial financial support was obtained, for the basic theory, from AFOSR under Grant 91-0140 to Northwestern University and, for experimental studies, from the Center for Advanced Cement-Based Materials at Northwestern University. Further partial support was received from Institute für Werkstoffe im Bauwesen, Stuttgart University, Stuttgart, Germany.

\section{APPENDIX. REFERENCES}

Bažant, Z. P., and Oh. (1983). "Crack band theory for fracture of concrete." Mat. and Struct., Paris, France, 93(16), 155-177.

Bažant, Z. P. (1984). "Size effect in blunt fracture: concrete, rock, metal." J. Engrg. Mech., ASCE, 110(4), 518-535.

Bažant, Z. P., and Kim, J. K. (1984). "Size effect in shear failure of longitudinally reinforced beams." J. Am. Concrete Inst., 81(5), 456-468.

Bažant, Z. P. (1986). "Mechanics of distributed cracking." Appl. Mech. Rev., Vol. $39,675-705$.

Bažant, Z. P. (1987). "Fracture energy of heterogeneous materials and similitude." Proc., SEM-RILEM Int. Conf. on Fracture of Concrete and Rock, S. P. Shah and S. E. Swartz, eds., Houston, 390-402.

Bažant, Z. P., and Cao, Z. (1987). "Size effect in punching shear failure of slabs." ACI Struct. J., Vol. 84, 44-53.

Bažant, Z. P., and Sun, H.-H. (1987). "Size effect in diagonal shear failure: influence of aggregate size and stirrups." ACI Mat. J., 84(4), 259-272.

Bažant, Z. P., and Prat, P. C. (1988). "Microplane model for brittle-plastic material. Parts I and II." J. Engrg. Mech., ASCE, 114(10), 1672-1702.

Bažant, Z. P., and Sener, S. (1988). "Size effect in pullout tests." ACI Mat. J., Vol. $85,347-351$.

Bažant, Z. P., Sener, S., and Prat, P. (1988). "Size effect tests of torsional failure of plain and reinforced concrete beams." Mat. and Struct., Paris, France, 21, 425430.

Bažant, Z. P., and Lin, F.-B. (1988). "Nonlocal smeared cracking model for concrete fracture." J. Engrg. Mech., ASCE, Vol. 114, 2493-2510.

Bažant, Z. P., and Ožbolt, J. (1990). "Nonlocal microplane model for fracture, damage, and size effect in structures." J. Engrg. Mech., ASCE, 116(11), 24852504.

Bažant, Z. P., and Xi, Y. (1991). "Statistical size effect in quasibrittle structures." J. Engrg. Mech., ASCE, 117(11), 2609-2640.

Bažant, Z. P., Tabbara, M. T., Kazemi, M. T., and Pijaudier-Cabot, G. (1990). "Random particle model for fracture of aggregates and fiber composites." J. Engrg. Mech., ASCE, 116(8), 1686-1705.

Bažant, Z. P., and Kazemi, M. T. (1991). "Size effect on diagonal shear failure of beams without stirrups." ACI Struct. J., Vol. 88, 268-276.

Bažant, Z. P., and Cedolin, L. (1991). Stability of structures: elastic, inelastic, fracture and damage theories. Oxford University Press, New York, N.Y.

Bažant, Z. P., and Kwon, Y. W. (1991). "Size effect in failure of short or slender reinforced concrete columns." Struct. Engrg. Rep. 91-12-1457s, Dept. of Civ. Engrg., Northwestern University, Evanston, III.

Bažant, Z. P., Kazemi, M. T., Hasegawa, T., and Mazars, J. (1991) "Size effect in Brazilian split-cylinder tests: measurements and fracture analysis." ACI Mat. J., 88(3), 325-332.

Bažant, Z. P. (1992). "New nonlocal damage concept based on micromechanics of crack interactions." Rep. 92-7/C457 n, Dept. of Civ. Engrg., Northwestern University, Evanston, Ill.; also J. Engrg. Mech., ASCE, 120(3), 593-617 (1994). 
Bhal, N. S. (1968). "Über den Einfluß der Balkenhohe auf die Schubtragfähtigkeit von einfeldrigen Stahlbetonbalken mit und ohne Schubbewehrung," doctoral thesis, Unversität Stuttgart, Stuttgart, Germany

Bocca, P., Carpinteri, A., and Valente, S. (1990). "Size effect in mixed mode crack propagation: softening and snap-back analysis." Engrg. Fracture Mech., 35, $159-70$.

Carpinteri, A. (1982). "Notch-sensitivity and fracture testing of aggregate materials." Engrg. Fracture Mech., 16(14), 467-481.

Carpinteri, A. (1986). Mechanical damage and crack growth in concrete. Martinus Nijhoff Publishers, Dordrecht, The Netherlands.

Cervenka, V., Pukl, R., and Eligehausen, R. (1990). "Computer simulation of anchoring technique in reinforced concrete beams." Proc., Int. Conf. Computer Aided Analysis and Design of Concrete Struct.; Part I, N. Bićanić et al., eds., Pineridge Press, Swansea, Wales, 1-21.

Chana, P.S. (1981). "Some aspects of modeling the behavior of reinforced concrete under shear loading." Tech. Rep. No. 543, Cement and Concrete Assoc., Wexham Springs.

de Borst, R. (1991). "Continuum models for discontinuous media." Proc., Int. RILEMIESIS Conf.; Fracture Processes in Concrete, Rock and Ceramics, Noordwijk, The Netherlands, 601-618.

de Borst, R., and Rots, J. G. (1989). "Occurrence of spurious mechanisms in computations of strain softening solids." Engrg. Comp., 6, 272-280.

Eligehausen, R., Fuchs, W., and Mayer, B. (1988). "Load-bearing behaviour of anchor fastenings in tension." Betonwerk + Fertigteil Technik, 12(Part 1), 826832, 1(Part 2), 29-35.

Eligehausen, R., Fuchs, W., Ick, U., Mallée R., Reuter, M., Schimmelpfenning, K., and Schmal, B. (1991). "Tragverhalten von Kopfbolzenverankerung bei zentrischer Zugbeanspruchung." Bauingenieur, Berlin, Germany (in German).

Eligehausen, R., and Sawade, G. (1989). "A fracture mechanics based description of the pull-out behavior of headed studs embedded in concrete." Fracture mechanics of concrete structures - RILEM report, L. Elfgren, ed., Chapman and Hall, London, England, 263-280.

Eligehausen, R., and Ožbolt, J. (1990). "Size effect in anchorage behavior." Proc., 8th European Conf. on Fracture Behaviour and Design of Mat. and Struct., Torino, Italy, 2671-2677.

Eligehausen, R., and Ožbolt, J. (1992). "Size effect in concrete structures." Application of fracture mechanics to reinforced concrete, A. Carpinteri, ed., Elsevier Applied Science, Torino, Italy, 17-44.

Eligehausen, R., Bouška, P., Cervenka, V., and Pukl, R. (1992). "Size effect of the concrete cone failure load of anchor bolts," Fram $\operatorname{CoS} 1$, Z. P. Bažant, ed., Elsevier Applied Science, Breckenridge, 517-525.

Gogotsi, G. A., Groushevski, Y. L., and Strelov, K. K. (1978). "The significance of non-elastic deformation in the fracture of heterogeneous ceramic materials." Ceramuqia Int., 4(3), 113-118.

Heilmann, H. G. (1969). "Beziehungen zwischen Zug- und Druckfestigkeit des Betons." Beton, Berlin, Germany, 2, 68-72 (in German).

Hawkins, N. M. (1985). "The role of fracture mechanics in conventional reinforced concrete design." Proc., NATO Advanced Res. Workshop on Application of Fracture Mechanics to Cementious Composites, held at Northwestern University, Evanston, Ill., S. P. Shah, ed., Martinus Nijhoff Publishers, Boston, Mass., 639666.

Hillerborg, A., Modéer, M., and Petersson, P. E. (1976). "Analysis of crack formation and crack growth in concrete by means of fracture mechanics and finite elements." Cement and Concrete Res., Vol. 6, 773-782.

Hillerborg, A. (1985). "The theoretical basis of a method to determine the fracture energy $G_{F}$ of concrete." Mat. and Struct., Paris, France, 18(106), 291-296.

Hillerborg, A. (1989). "Fracture mechanics and the concrete codes." Fracture mechanics: applications to concrete; ACI-SPI18, V. Li and Z. P. Bažant, eds., American Concrete Institute (ACI), Detroit, Mich., 157-170. 
Homeny, J., Darroudi, T., and Bradt, R. G. (1980). "J-integral measurements of the fracture of $50 \%$ aluminia refractories." J. Am. Ceramic Soc., 63(5-6), 326331.

Hsu, T. T. C. (1968). "Torsion of structural concrete-plain concrete rectangular sections." Torsion of structural concrete (SP-18), American Concrete Institute (ACI), Detroit, Mich., 203-238.

Humphreys, R. (1957). "Torsional properties of prestressed concrete." Struct. Engr., London, England, 35(6), 213-224.

Iguro, M.. Shioya, T., Nojiri, Y., and Akiyama, H. (1985). "Experimental studies on shear strength of large reinforced concrete beams under uniformly distributed load." Concrete Library Int. , Japan Society of Civil Engineers, Tokyo, Japan, (5), $137-154$

Ingraffea, A. R. (1985). "Fracture propagation in rock." Mechanics of geomaterials: rocks, concretes, soils, Z. P. Bažant, ed., John Wiley and Sons, Inc., New York, N.Y., 219-258.

Kani, G. N. J. (1967). "How safe are our large reinforced concrete beams?" J. Am. Concrete Inst., 64(3), 128-141.

Leonhardt, F., and Walter, R. (1962). "Beiträge zur Behandlung der Schubprobleme im Stahlbetonbau." Beton- und Stahlbetonbau, Berlin, Germany, (Mar.), 56-64, (Jun.), 141-149 (in German)

Marti, P. (1989). "Size effect in double-punch tests on concrete cylinders." $A C I$ Mat. J., 86(6), 597-601.

McMullen, A. E., and Daniel, H. R. (1972). "Torsional strength of Iongitudinally reinforced concrete members of rectangular cross-section," doctoral thesis, West Virginia University, Morgantown, W. Va.

Mihashi, H., and Zaitsev, J. W. (1981). "Statistical nature of crack propagation." Section 4-2; Rep. to RILEM TC 50-FMC, F. W. Wittmann, ed., RILEM, Paris, France.

Mihashi, H. (1983). "Chapter 4.3: a stochastic theory for fracture of concrete." Fracture mechanics of concrete, F. H. Wittman, ed., Elsevier, New York, N.Y., $301-340$.

Ožbolt, J., and Eligehausen, R. (1991). "Analysis of reinforced concrete beams without shear reinforcement using nonlocal microplane model." Proc., Int. RILEM/ESIS Conf., Fracture Processes in Concrete, Rock and Ceramics, Noordwijk, The Nederlands, 919-930.

Ožbolt, J. (1992). "Smeared crack analysis-new nonlocal microcrack interactions approach." Internal Rep. No. 4/14-92/19, Institut für Werkstoffe im Bauwesen, Stuttgart University, Stuttgart, Germany.

Ožbolt, J., and Petrangeli, M. (1993). "Improved microplane model for concrete." Internal Rep. No. 4/17-93/5, Institut für Werkstoffe im Bauwesen, Stuttgart University, Stuttgart, Germany.

Petersson, P. E. (1981). "Crack growth and development of fracture zones in plain concrete and similar materials." Rep. TVBM-1006, Div. of Building Materials, Lund Inst. of Tech., Lund, Sweden.

Petrangeli, M., and Ožbolt, J. (1992). "Smeared crack approaches-material modeling." Internal Rep. No. 4/15-92/22, Institut für Werkstoffe im Bauwesen, Stuttgart University, Stuttgart, Germany.

Reinhardt, H. W. (1981a). "Similitude of brittle fracture of structural concrete." IABSE Colloquium on Adv. in Reinforced Concrete, Delft, The Netherlands, 175184.

Reinhardt, H. W. (1981b). "Maßtabseinfluße in Schubversuchen im sicht der Bruchmechanik." Beton und Stahlbetonbau, Berlin, Germany, 76(1), 19-21 (in German).

Rüsch, H., Haugli, F. R., and Mayer, H. (1962). "Schubversuche an StahlbetonRechteckbalken mit gleichmäßig verteilter Belastung," Bull. No. 145, Deutscher Ausschuß für Stahlbeton, Berlin, Germany, 4-30 (in German).

Rots, J. G. (1988). "Computational modelling of concrete fracture," doctoral thesis, Delft University of Technology, Delft, The Netherlands.

Rots, J. G. (1992). "Removal of finite elements in strain-softening analysis of tensile 
fracture." Fram $\operatorname{CoS} 1$, Z. P. Bažant, ed., Elsevier Applied Science, Breckenridge, $330-338$.

Sener, S. (1993). "Size effect in failure of splices of reinforcing bars in concrete." Rep., Technical University of Ankara, Ankara, Turkey.

Taylor, F. P. J. (1972). "The shear strength of large beams." J. Struct. Engrg., ASCE, 98, 2473-2490.

van Mier, J. G. M. (1992). "Scaling in tensile and compressive fracture of concrete." Application of fracture mechanics to reinforced concrete, A. Carpinteri, ed., Elsevier Applied Science, Torino, Italy, 95-136.

Walraven, J. (1978). "The influence of depth on the shear strength of lightweight concrete beams without shear reinforcement." Stevin Lab. Rep. No. 5-78-4, Delft University of Technology, Delft, The Netherlands.

Walraven, J., and Lehwalter, N. (1990). "Einfluß des Maßtabs in schubbeanspruchten Bauteilen ohne Schubbewehrung," Beton- und Stahlbetonbau 85, Berlin, Germany, 9, 228-232 (in German).

Walraven, J. (1990). "Scale effects in beams with unreinforced webs, loaded in shear." Progress in Concrete Res; Annu. Rep., Delft University of Technology, Delft, The Netherlands, Vol. 1, 101-112.

Walsh, P. F. (1976). "Crack initiation in plain concrete." Mag. Concrete Res., Vol. $28,37-41$.

Wittman, F. H., Mihashi, H., and Noumura, H. (1990). "Size effect on fracture energy of concrete." Engrg. Fracture Mech., 35, 107-115. 